\title{
POTENSI GULMA SEBAGAI PESTISIDA NABATI
}

\author{
Dina Indriyanti Octavia ${ }^{1}$, Dewi Rahyuni ${ }^{2}$, Nasirudin ${ }^{3}$ \\ ${ }^{123}$ Institut Teknologi Yogyakarta (STTL-YLH), Yogyakarta, \\ Indonesia
}

INTISARI

Penggunaan pestisida kimia dapat membahayakan lingkungan, oleh karena itu adanya pestisida nabati diperlukan untuk dapat menjaga lingkungan tetap terjaga. Penggunaan pestisida nabati dari gulma Babandotan, Siam dan Ajeran untuk mengendalikan hama ulat grayak dapat menjaga lingkungan tetap sehat, selain itu gulma yang terbuang dapat bernilai lebih ekonomis dan hama ulat grayak dapat dikendalikan tanpa penggunaan bahan kimia. Pestisida nabati dapat mengendalikan hama ulat grayak dengan adanya kandungan Saponin dan Alkaloid dalam ekstrak gulma yang dapat mengurangi nafsu makan, menimbulkan keracunan bagi hama hingga menimbulkan kematian hama ulat Grayak. Tujuan penelitian ini adalah mengetahui pengaruh jenis dan konsentrasi ekstrak gulma terhadap pengendalian hama ulat Grayak (Spedoptera litura), mengetahui formula antara jenis dan konsentrasi ekstrak gulma yang terbaik untuk mengendalikan hama ulat Grayak (Spedoptera litura)serta mengetahui korelasi antara konsentrasi ekstrak gulma untuk setiap jenis gulma terhadap kematian hama ulat Grayak (Spedoptera litura).

Penelitian pembuatan pestisida nabati dari ekstrak gulma Babandotan, Siam dan Ajeran dilakukan dengan merendam daun gulma yang telah dihancurkan selama 72 jam untuk mendapatkan ekstrak gulma yang kemudian diencerkan dengan variasi konsentrasi masing masing gulma $0 \%$ (control), $15 \%, 30 \%, 45 \%, 60 \%, 75 \%$ dan $90 \%$. Pengaplikasian pestisida nabati dilakukan dengan menyemprotkan pada daun sawi dan ulat Grayak 5 kali penyemprotan setiap 5 menit hingga ulat Grayak pergi secara keseluruhan atau hingga terdapat kematian ulat Grayak. Pengujian kandungan Alkaloid dan Saponin pada ekstrak gulma dilakukan di LPPT UGM dengan metode Spektrofotometri UV-vis.

Hasil pengujian kandungan Alkaloid dan Saponin yang diperoleh dari pengujian di Laboratorium LPPT UGM pada ekstrak Babandotan $(132,03 \mu \mathrm{L} / \mathrm{mL}$ dan $1,57 \% \mathrm{~b} / \mathrm{b})$, Siam $(101,10 \mu \mathrm{L} / \mathrm{mL}$ dan $1,76 \% \mathrm{~b} / \mathrm{b})$ dan Ajeran $(42,74 \mu \mathrm{L} / \mathrm{mL}$ dan $1,79 \% \mathrm{~b} / \mathrm{b})$. Hasil penelitian yang dilakukan berdasarkan uji BNT bahwa jenis dan konsentrasi ekstrak gulma berpengaruh nyata terhadap pengendalian hama ulat grayak, dan yang paling efektif mengendalikan dilihat dari parameter waktu kematiannya adalah pada ekstrak Babandotan dengan dosis $90 \%$ dengan waktu kematian rata-rata 313,3 menit. Berdasarkan uji regresi linier, jenis dan konsentrasi ekstrak gulma terhadap kematian ulat memiliki hubungan yang lemah, signifikan dan tidak searah.

Kata Kunci : Gulma, Pestisida Nabati, Hama, Ulat Grayak, Babandotan, Siam, Ajeran 


\title{
POTENTIAL OF WEED AS A VEGETABLE PESTICIDE
}

\begin{abstract}
The use of chemical pesticides can harm the environment, therefore allowing vegetable pesticides is needed to maintain the environment. The use of plant-based pesticides from Babandotan, Siam and Ajeran weeds to control army worm pests can keep the environment healthy, besides wasted weeds can be worth more and armyworm pests can be played without using chemicals. Vegetable pesticides can control armyworm pests with the content of Saponins and Alkaloids in weed extracts which can reduce appetite and gifts of poisoning for pests.The purpose of this research isknowing the influence of typeand concentration of weed extract to control Army worm(Spedoptera litura), knowing the formula between type and concentration of the best weed extract to control the Army worm (Spedoptera litura) as well, and knowing the correlation between concentration of weed extract for each type of weed against the death of the Army worm (Spedoptera litura).

The research of vegetable pesticides from Babandotan, Siam and Ajeran weed extractsdone by soaking the leaves of weeds that have been crushed for 72 hours to get weed extract which is then diluted with variations in the concentration of each weed $0 \%$ (control), 15\%, 30\%, 45\%, 60\%, 75\% and 90\%.The application of vegetable pesticides is done by spraying on mustard leaves and Armywormon 5 times spraying every 5 minutes until the Army worm leaves as a whole or until there is a death of the army worm.esting of the content of alkaloids and saponins in weed extracts was carried out at the UGM LPPT using the UV-vis Spectrophotometry method.

Test results of Alkaloids and Saponins obtained from testing at the UGM LPPT Laboratory in Babandotan extract (132.03 $\mu \mathrm{L} / \mathrm{mL}$ and $1.57 \% \mathrm{~b} / \mathrm{b}$ ), Siam $(101.10 \mu \mathrm{L} / \mathrm{mL}$ and $1.76 \% \mathrm{~b} / \mathrm{b})$ and Ajeran $(42.74 \mu \mathrm{L} / \mathrm{mL}$ and $1.79 \% \mathrm{~b} / \mathrm{b}$ ). The results of the research were carried out based on the LSD test that the type and concentration of weed extract significantly affected the army worm pest control, and the most effective control seen from the parameters of the time of death was Babandotan extract $90 \%$ with an average death time of 313.3 minutes. Based on linear regression test, the type and dosage of weed extracts against armyworm deaths have a weak, significant and unidirectional relationship.
\end{abstract}

Keywords: Weeds, Vegetable Pesticides, Pests, Army worm, Babandotan, Siam, Ajeran

\section{PENDAHULUAN}

Usaha memperkecil dampak negatif penggunaan pestisida kimiawi yang tidak bijaksana, maka dalam Peraturan Pemerintah (PP) No. 6 tahun 1995 pasal 3 telah ditetapkan bahwa perlidungan tanaman dilaksanakan melalui sistem Pengendalian Hama Terpadu (PHT) dalam pasal 19 dinyatakan bahwa penggunaan pestisida dalam rangka pengendalian OPT merupakan alternatif terakhir. Sehubungan dengan hal tersebut, maka perlu 
dicari pengendalian yang efektif terhadap hama sasaran namun aman terhadap organisme bukan sasaran dan lingkungan. Salah satu komponen PHT yang mempunyai prospek untuk dikembangkan adalah pestisida nabati, yaitu pestisida yang bahannya berasal dari tumbuhtumbuhan.

Selama ini para petani di Indonesia masih menggunakan pestisida kimia untuk mengendalikan hama (Semangun, 2000). Indonesia merupakan negara yang paling banyak menggunakan pestisida kimia di Asia, setelah Cina dan India (Wahyuni, 2010). Pengendalian dengan menggunakan senyawa kimia memang memberikan hasil yang cepat dan lebih efektif, namun juga menimbulkan dampak negatif, diantaranya menghasilkan residu racun yang berdampak buruk bagi lingkungan dan kesehatan manusia. Keadaan inilah yang menjadi dasar pertimbangan untuk mencari teknik pengendalian hama yang lebih ramah lingkungan yang sangat dibutuhkan. Salah satu pilihan yang lebih aman adalah pemanfaatan bahan dari tumbuhan, termasuk jenis gulma, dalam bentuk pestisida nabati (Asmaliyah et al., 2010).

Gulma bisa menjadi ancaman karena selain menimbulkan kompetisi unsur hara dari dalam tanah, gulma juga bisa jadi rumah sekunder beberapa jenis hama. Namun beberapa dari jenis tanaman yang biasa dianggap gulma justru dapat mengendalikan hama seperti tanaman Babandotan, Siam dan Ajeran yang memiliki senyawa aktif seperti Alkaloid dan Saponin yang dapat mengendalikan hama ulat. Beberapa laporan menyebutkan bahwa ekstrak gulma siam dapat digunakan untuk mengendalikan beberapa jenis hama dan bahkan bersifat toksik (Thodenet al., 2007).

\section{TINJAUAN PUSTAKA}

\section{Organisme Tanaman \\ Pengganggu} Kehidupan makhluk hidup di daerah tropika sangat melimpah dan tidak terkendali perkembangannya oleh musim, termasuk suhu, kelembaban dan kehidupan Organisme Pengganggu Tanaman (OPT), yang merusak tanaman dan produknya (Soesanto, 2017).

Sekitar 67.000 OPT yang berbeda spesies termasuk patogen tanaman, gulma, invertebrata dan beberapa spesies vertebrata hama tanaman bersama-sama menyebabkan sekitar $40 \%$ pengurangan hasil panen dunia. Kerugian tanaman yang disebabkan oleh hama dan penyakit tanaman melemahkan ketahanan pangan bersama kendala lainnya, seperti cuaca buruk, tanah yang miskin hara dan terbatasnya akses petani ke pengetahuan teknis (Soesanto, 2017).

\section{Ulat Grayak}


Menurut (Pitoyo, 2005) Spodoptera litura ini disebut ulat grayak karena ulat ini dalam jumlah yang sangat besar sampai ribuan menyerang dan memakan tanaman pada waktu malam hari sehingga tanaman akan habis dalam waktu yang singkat. Serangan ulat grayak ini perlu di waspadai karena pada siang hari tidak tampak dan biasanya bersembunyi di tempat yang gelap dan di dalam tanah maupun bagian belakang daun, namun pada malam hari ulat grayak melakukan aktivitas serangan yang hebat dan bahkan dapat menyebabkan kegagalan panen.

\section{Tanaman Babandotan}

Babandotan tergolong ke dalam tumbuhan terna semusim/ setahun, tumbuh tegak atau bagian bawahnya berbaring, tingginya sekitar 30-90 cm, dan bercabang.

Babandotan

diketahui mengandung monoterpen, sesquiterpen, kromen, kromon, benzofuran, kumarin, flavonoid, triterpen, sterol, alkaloid dan minyak atsiri (Kamboj, 2008). Babadotan memiliki kandungan bahan aktif terutama di bagian daunnya yaitu alkaloid, saponin, flavonoid, polifenol, sulfur dan tannin (Grainge, 1988).

\section{Tanaman Siam}

Gulma siam merupakan tangguh karena batangnya yang keras, berkayu dan perakarnya kuat dan dalam. Selain itu gulma siam menghasilkan biji yang banyak dan mudah tersebar dengan bantuan angin karena adanya rambut palpus. Tanaman Siam hidup di darat atau tanah yang kering seperti tegalan atau kebun. Tumbuhan ini mengandung senyawa fenol, alkaloid, triterpenoid, tanin, flavonoid (eupatorin) dan limonen. Kandungan tanin yang terdapat dalam daun gulma siam adalah 2,56\% (Romdonawati, 2009).

\section{Tanaman Ajeran}

Ajeran merupakan rumput yang termasuk gulma fakultatif yang tumbuh di darat dan banyak ditemui di pinggir jalan maupun tumbuh di tegalan/ ladang yang bertanah kering. Bahan kimia yang terkandung dalam ajeran adalah flavonoid, terpenoid, fenilpropanoid, lemak dan benzenoid (Malik, 2013). Tanaman gulma Ajeran mengandung senyawa yang bersifat toksik yaitu flavonoid, alkaloid, saponin dan terpenoid. Senyawa ini dapat membunuh hama sasaran dengan cara masuk ke pencernaan melalui makanan yang mereka makan (Jumar, 2000).

\section{METODE PENELITIAN}

\section{Lokasi Penelitian}


Penelitian pembuatan pestisida nabati dan aplikasinya dilakukan di tempat tinggal peneliti di desa Ngruweng RT.01 RW.01, Wiro, Bayat, Klaten, Jawa Tengah. Pengujian kandungan senyawa pada tanaman gulma Babadotan, Siam dan Ajeran dilakukan di LPPT UGM.

\section{Objek Penelitian}

Obyek dalam penelitian adalah ekstrak tanaman gulma Babandotan, Siam dan Ajeran sebagai pestisida nabati.

\section{Variabel Penelitian}

\section{Variabel Bebas}

a. Jenis Gulma : Tanaman

Babandotan (Ageratum conzyoides), Tanaman Siam (Cromolaena odorata), Tanaman Ajeran (Biden pilosa).

b. Konsentrasi : $\quad 0 \%$ (kontrol), 15\%, 30\%, 45\%, $60 \%, 75 \%$ dan $90 \%$

\section{Variabel Terikat}

a. Waktu kematian hama ulat grayak (Spodoptera litura).

b. Fisiologis (lincah dan lemas) dan morfologis (warna dan bentuk) ulat grayak (Spodoptera litura).

c. Volume pestisida nabati.

\section{Analisis Data}

a. Untuk mengetahui pengaruh beda nyata antara jenis dan konsentarsi ekstrak gulma terhadap pengendalian hama ulat grayak maka dilakukan analisis statistik menggunakan Anova $\alpha 5 \%$.

b. Apabila uji F Tabel menunjukkan beda nyata, maka dilanjutkan uji BNT pada taraf $\alpha 5 \%$ (Fisher, 1935).

c. Untuk mengetahui korelasi antara konsentarsi dengan waktu kematian ulat grayak, maka dilakukan analisis regresi korelasi.

\section{HASIL DAN PEMBAHASAN}

1. Kandungan Alkaloid dan Saponin

Pengujian kandungan Alkaloid dan Saponin pada tanaman gulma Babandotan, Siam dan Ajeran dilakukan di LPPT UGM dengan metode Spektrofotometri UV-vis.

Tabel 1. Kandungan Alkaloid dan Saponin pada Ekstrak Tanaman Gulma

\begin{tabular}{|l|l|l|l|l|l|}
\hline \multirow{2}{*}{ No. } & \multirow{2}{*}{ Parameter } & \multirow{2}{*}{ Satuan } & \multicolumn{4}{|l|}{ Jenis Tanaman } \\
\cline { 3 - 6 } & & & Babandotan & Siam & Ajeran \\
\hline 1. & Saponin & $\% \mathrm{~b} / \mathrm{b}$ & 1,57 & 1,76 & 1,79 \\
2. & Alkaloid & $\mu \mathrm{L} / \mathrm{mL}$ & 132,03 & 101,10 & 42,74 \\
\hline
\end{tabular}

Sumber: Data Primer, 2018

\section{Kondisi Fisiologis Ulat}

Hasil penelitian menunjukkan bahwa ulat yang disemprot dengan pestisida nabati dari ekstrak daun gulma Babandotan, Gulma dan Siam pada setiap ulangan dengan konsentrasi $15 \%, 30 \%, 45 \%$, 
$60 \%, \quad 75 \%$ dan $90 \%$ dapat membuat lemas ulat, sedangkan pada konsentrasi $0 \%$ ulat tetap bergerak dengan lincah.

Hal ini sesuai menurut Aminah (2000) yang menyatakan bahwa pada ekstrak daun gulma konsentrasi 15\%, $30 \%, 45 \%, 60 \%, 75 \%$ dan $90 \%$ terkandung senyawa Alkaloid yang bersifat mengurangi nafsu makan. Kondisi ulat yang tidak bernafsu makan menyebabkan ulat akan menjadi lemas, aktifitas menurun serta mengalami perubahan warna dan bentuk, sedangkan pada konsentrasi $0 \%$ sebagai kontrol larutan tidak mengandung Alkaloid, sehingga ulat masih lincah bergerak disekitar daun dan melakukan aktivitas makan. Selain itu, pada konsentrasi 0\% kenampakan daun masih berwarna hijau segar sehingga ulat tertarik untuk mendekat.

Tabel 2. Kondisi Fisiologis Ulat Grayak

\begin{tabular}{|c|c|l|l|l|}
\hline \multicolumn{2}{|c|}{ Gulma } & \multicolumn{2}{c|}{ Kondisi Fisiologis } \\
\hline Jenis & Dosis & Ulangan 1 & Ulangan 2 & Ulangan 3 \\
\hline \multirow{4}{*}{ Babandotan } & $0 \%$ & Lincah & Lincah & Lincah \\
\cline { 2 - 5 } & $15 \%$ & Lemas & Lemas & Lemas \\
\cline { 2 - 5 } & $30 \%$ & Lemas & Lemas & Lemas \\
\cline { 2 - 5 } & $45 \%$ & Lemas & Lemas & Lemas \\
\cline { 2 - 5 } & $60 \%$ & Lemas & Lemas & Lemas \\
\cline { 2 - 5 } & $75 \%$ & Lemas & Lemas & Lemas \\
\cline { 2 - 5 } & $90 \%$ & Lemas & Lemas & Lemas \\
\hline \multirow{5}{*}{ Siam } & $0 \%$ & Lincah & Lincah & Lincah \\
\cline { 2 - 5 } & $15 \%$ & Lemas & Lemas & Lemas \\
\cline { 2 - 5 } & $30 \%$ & Lemas & Lemas & Lemas \\
\cline { 2 - 5 } & $45 \%$ & Lemas & Lemas & Lemas \\
\cline { 2 - 5 } & $60 \%$ & Lemas & Lemas & Lemas \\
\cline { 2 - 5 } & $75 \%$ & Lemas & Lemas & Lemas \\
\cline { 2 - 5 } & $90 \%$ & Lemas & Lemas & Lemas \\
\hline \multirow{5}{*}{ Ajeran } & $0 \%$ & Lincah & Lincah & Lincah \\
\cline { 2 - 5 } & $15 \%$ & Lemas & Lemas & Lemas \\
\cline { 2 - 5 } & $30 \%$ & Lemas & Lemas & Lemas \\
\cline { 2 - 5 } & $45 \%$ & Lemas & Lemas & Lemas \\
\cline { 2 - 5 } & $60 \%$ & Lemas & Lemas & Lemas \\
\cline { 2 - 5 } & $75 \%$ & Lemas & Lemas & Lemas \\
\cline { 2 - 5 } & $90 \%$ & Lemas & Lemas & Lemas \\
\hline
\end{tabular}

Sumber: Data Primer, 2018

\section{Kondisi Morfologis Ulat}

Hasil

penelitian

menunjukkan bahwa ulat yang disemprotkan dengan pestisida nabati pada setiap ulangan pada konsentrasi $15 \%, 30 \%, 45 \%$, $60 \%, 75 \%$ dan $90 \%$ terjadi perubahan warna ulat grayak dari hijau segar menjadi hitam setelah dilakukan penyemprotan, sedangkan pada konsentrasi $0 \%$ ulat tidak mengalami perubahan warna. Selain itu pada ulat yang mengalami perubahan warna menjadi hitam juga terjadi perubahan bentuknya yang mulai berkerut.

Menurut Anonim (2017), perubahan warna hitam pada ulat grayak menandakan bahwa ulat grayak telah mengalami keracunan akibat dari kandungan Saponin dalam ekstrak gulma yang bersifat toksik. Hal ini dikuatkan juga dengan pernyataan Pratama (2010) bahwa Saponin masuk ke tubuh ulat melalui melalui saluran pernapasan yang ada di permukaan tubuh yang kemudian masuk kedalam tubuh saat ekstrak gulma disemprotkan kemudian merusak dan membuat korosi bagian dalam tubuh ulat. Selain itu, Saponin dapat meracuni ulat melalui mulut ketika masih ada ulat yang melakukan aktivitas makan 
dengan merusak dan membuat korosi saluran pencernaan.

Tabel 3. Kondisi Morfologis

\begin{tabular}{|c|c|c|c|c|}
\hline \multicolumn{2}{|c|}{ Gulma } & \multicolumn{3}{|c|}{ Kondisi Morfologis } \\
\hline Jenis & Dosis & Ulangan 1 & \begin{tabular}{|l|} 
Ulangan 2 \\
\end{tabular} & \begin{tabular}{|l|} 
Ulangan 3 \\
\end{tabular} \\
\hline \multirow{7}{*}{ Babandotan } & $0 \%$ & Hijau & Hijau & $\begin{array}{l}\text { Hijau } \\
\end{array}$ \\
\hline & $15 \%$ & Hitam & Hitam & Hitam \\
\hline & $30 \%$ & Hitam & Hitam & Hitam \\
\hline & $45 \%$ & Hitam & Hitam & Hitam \\
\hline & $60 \%$ & Hitam & Hitam & Hitam \\
\hline & $75 \%$ & Hitam & Hitam & Hitam \\
\hline & $90 \%$ & Hitam & Hitam & Hitam \\
\hline \multirow{7}{*}{ Siam } & $0 \%$ & Hijau & Hijau & Hijau \\
\hline & $15 \%$ & Hitam & Hitam & Hitam \\
\hline & $30 \%$ & Hitam & Hitam & Hitam \\
\hline & $45 \%$ & Hitam & Hitam & Hitam \\
\hline & $60 \%$ & Hitam & Hitam & Hitam \\
\hline & $75 \%$ & Hitam & Hitam & Hitam \\
\hline & $90 \%$ & Hitam & Hitam & Hitam \\
\hline \multirow{7}{*}{ Ajeran } & $0 \%$ & Hijau & Hijau & Hijau \\
\hline & $15 \%$ & Hitam & Hitam & Hitam \\
\hline & $30 \%$ & Hitam & Hitam & Hitam \\
\hline & $45 \%$ & Hitam & Hitam & Hitam \\
\hline & $60 \%$ & Hitam & Hitam & Hitam \\
\hline & $75 \%$ & Hitam & Hitam & Hitam \\
\hline & $90 \%$ & Hitam & Hitam & Hitam \\
\hline
\end{tabular}

Sumber: Data Primer, 2018

\section{Jumlah Ulat Mendekat pada 5 Menit Awal Penyemprotan Pertama}

Tabel 4. Jumlah Ulat Mendekat 5 Menit Pertama

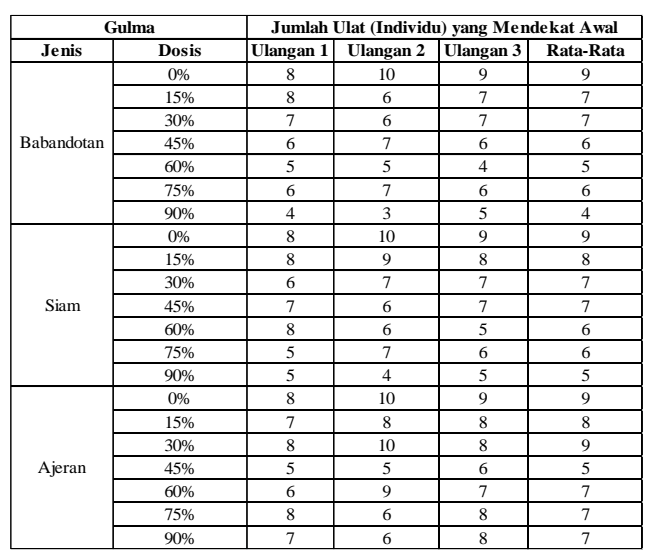

Sumber: Data Primer, 2018

Hasil penelitian menunjukkan bahwa variasi jenis dan konsentrasi ekstrak gulma berpengaruh terhadap jumlah hama ulat grayak yang mendekat awal pada daun sawi. Konsentrasi 0\% menunjukkan bahwa dari 10 ulat terdapat 9 ulat yang mendekat dan 1 ulat yang tidak mendekat. Hal ini dapat dipengaruhi oleh kondisi lingkungan dan kondisi ulat yang tidak dalam kondisi nafsu makan karena pada konsentrasi $0 \%$ tidak mengandung zat Alkaloid maupun Saponin yang berada pada ekstrak gulma. Konsentrasi 15\%, $30 \%, 45 \%, 60 \%$, $75 \%$ dan $90 \%$ pada tiap jenis ekstrak gulma menunjukkan rata-rata ulat yang mendekat mulai dari 4-8 ulat. Jumlah ulat yang mendekat terbanyak adalah 8 ulat terjadi pada ekstrak gulma Siam dan Ajeran dengan konsentrasi $15 \%$, sedangkan jumlah ulat yang paling sedikit terdapat pada ektrak gulma Babandotan dengan konsentrasi $90 \%$.

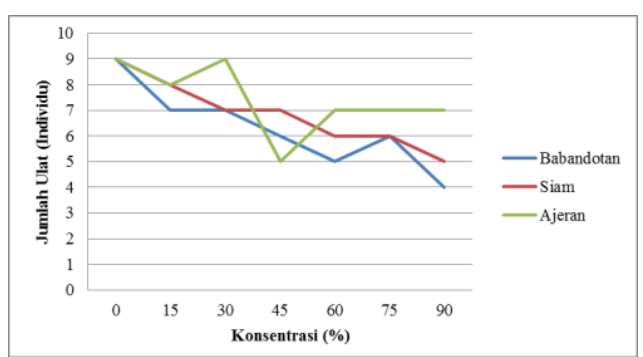

Sumber: Data Primer, 2018

Gambar 1. Jumlah Ulat Mendekat 5 Menit Awal

Grafik menunjukkan jumlah ulat yang mendekat tertinggi pada konsentrasi $0 \%$ dan jumlah ulat mendekat terendah pada ekstrak gulma Babandotan konsentrasi 90\%. 
Hasil pengamatan selama 5 menit pertama setelah penyemprotan menunjukkan masih banyak ulat yang mendekat pada daun sawi. Menurut Aminah (2001), jumlah ulat yang masih mendekat menunjukkan bahwa daun sawi masih disukai ulat. Ulat masih tertarik dengan daun sawi melalui kenampakannya yang masih segar dan hijau. Ulat yang mendekat pada daun sawi yang disemprotkan tidak langsung mengalami aktivitas makan setelah berada di daun sawi.Beberapa ulat memperlihatkan aktivitas tidak ingin memakan daun sawi. Hal ini disebabkan kandungan Alkaloid dan Saponin yang memiliki rasa pahit, sehingga ulat tidak memiliki nafsu makan pada daun sawi.

Hasil uji Anova diperoleh F hitung sebesar 10,617 dan $F$ tabel yang diperoleh dari Tabel Distribusi $F$ pada tingkat signifikasi $\alpha \quad 0,05$ sebesar 1,814. Hasil ini menunjukkan bahwa nilai Ftabel < Fhitung, sehingga jenis dan konsentrasi ekstrak gulma sebagai pestisida nabati berpengaruh nyata terhadap pengendalian hama ulat grayak.

\section{Jumlah Ulat Mendekat Akhir}

Tabel 5. Jumlah Ulat Mendekat Akhir

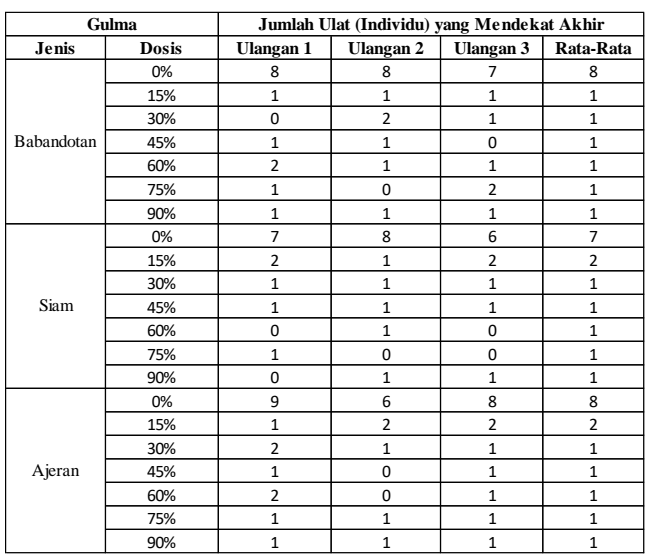

Sumber: Data Primer, 2018

Tabel 5 menunjukkan jumlah rata-rata ulat yang tinggal di daun sawi hingga akhir penyemprotan dengan ditandai seluruh ulat yang meninggalkan daun sawi atau hingga terjadi kematian. Rata-rata ulat yang mendekat akhir berjumlah 1-2 ulat. Jumlah 2 ulat terdapat pada gulma Siam 15\% dan Ajeran 15\%, sedangkan pada gulma Siam, Ajeran dan Babandotan pada konsentrasi $30 \%, 45 \%, 60 \%, 75 \%$ dan $90 \%$ serta Babandotan konsentrasi 15\%, ratarata ulat yang mendekat akhir berjumlah satu ulat.

Ekstrak gulma yang dapat membuat ulat grayak semuanya menjauh dari daun sawi terjadi pada ekstrak daun Babandotan konsentrasi $30 \%$, 45\% dan 75\%, ekstrak daun Siam pada konsentrasi 60\%, 75\% dan $90 \%$, serta pada ekstrak daun Ajeran pada konsentrasi $45 \%$ dan $60 \%$. Menjauhnya ulat grayak dari daun sawi karena adanya kandungan 
Alkaloid pada ekstrak daun gulma yang memberikan rasa pahit, sehingga nafsu makan ulat berkurang kemudian menjauh dari daun sawi.Ulat yang masih berada di daun sawi karena masih tertarik dengan kenampakan daun sawi, namun tidak ada aktivitas makan karena rasa daun sawi yang pahit bercampur dengan ekstrak gulma (Aminah, 2001).

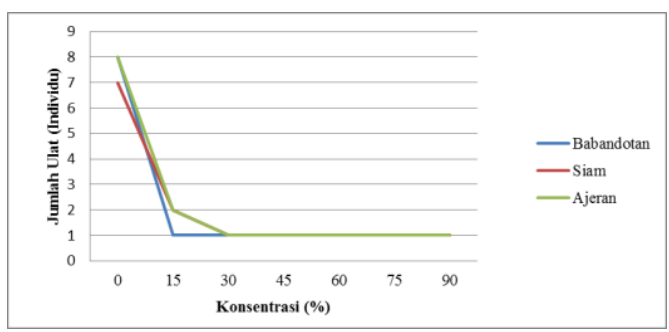

Sumber: Data Primer, 2018

Gambar 2. Jumlah Ulat Mendekat 5 Menit Awal

Grafik pada Gambar 2 menunjukkan bahwa jenis dan konsentrasi ekstrak gulma pada konsentrasi 15\%, 30\%, 45\%, 60\%, $75 \%$ dan $90 \%$ memiliki garis pada titik yang lebih rendah dari konsentrasi $0 \%$ atau control, sehingga ekstrak gulma dapat mengendalikan hama ulat terhadap jumlah ulat mendekat.

Hasil uji anova diperoleh $\mathrm{F}$ hitung yang diperoleh yaitu sebesar 35,367 dan F tabel yang diperoleh dari Tabel Distribusi F pada tingkat signifikasi $\alpha \quad 0,05$ sebesar 1,814 . Hasil ini menunjukkan bahwa nilai Ftabel < Fhitung, sehingga jenis dan konsentrasi ekstrak gulma sebagai pestisida nabati berpengaruh nyata terhadap pengendalian hama ulat grayak.

\section{Waktu Kematian Ulat Grayak}

Hasil penelitian pada Tabel 6 menunjukkan rata-rata waktu kematian tercepat terdapat pada penyemprotan ekstrak gulma Babandotan $90 \%$ dengan waktu kematian 313,3 menit, sedangkan waktu kematian ulat terlama terdapat pada gulma Ajeran $15 \%$.

Kematian ulat grayak disebabkan karena kandungan Alkaloid dan Saponin pada ekstrak gulma. Menurut Anonim (2017), bahwa Alkaloid mengendalikan hama dengan rasa pahit saat ulat mendekat dan mencoba makan daun sawi yang telah disemprotkan. Ulat yang makan daun sawi yang telah disemprotkan ekstrak gulma akan kehilangan nafsu makan karena rasanya yang pahit, sehingga ulat akan lemas dan mempengaruhi aktivitasnya yang dapat berakibat kematian.

Kandungan Saponin pada ekstrak gulma dapat mengendalikan hama ulat grayak dengan meracuni ulat melalui daun sawi yang dimakan dan merusak pencernaan serta dengan mengganggu saluran pernafasan yang terdapat pada kulit ulat sehingga ulat kemudian mengalami kematian (Pratama, 2010). Ulat yang mengalami keracunan ditandai dengan perubahan warna ulat menjadi hitam. 


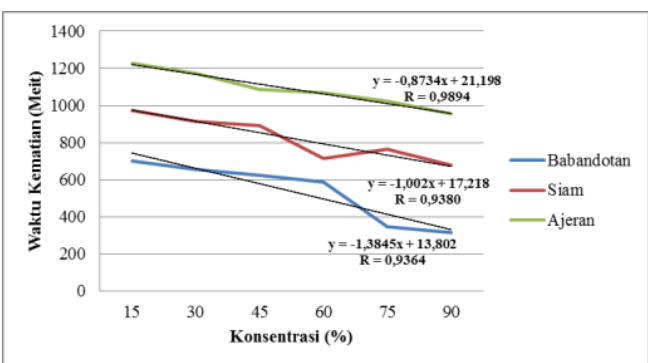

Sumber: Data Primer 2018

Gambar 3. Waktu Kematian Ulat Grayak

Hasil grafik yang tergambar juga menunjukkan bahwa semakin tinggi konsentrasi ekstrak daun gulma tidak memberikan pengaruh terhadap kecepatan kematian, hal ini ditunjukkan dengan gambaran grafik yang tidak lurus pada setiap jenis gulma.

Daya bunuh pestisida nabati terhadap hama ulat tidak secepat pestisida kimia, karena pestisida nabati memiliki kandungan bioaktif yang kurang kuat sehingga daya bunuhnya lemah. Oleh karena itu, pestisida ini lebih tepat disebut sebagai pestisida pengendali hama dan bukan sebagai pembasmi hama (Setiadi, 2012)

Tabel 6. Waktu Kematian Ulat Grayak

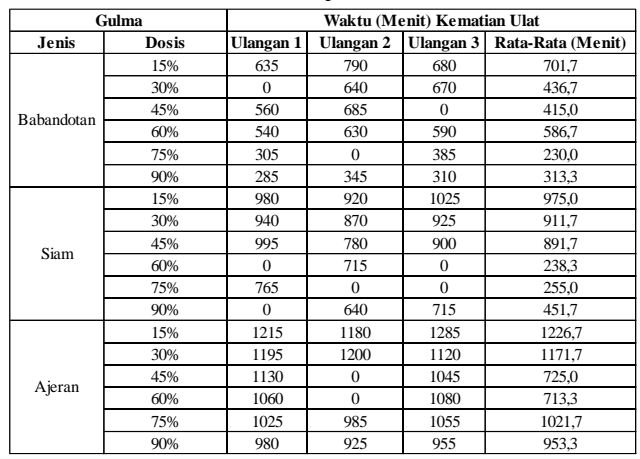

Sumber: Data Primer, 2018
Hasil perhitungan uji regresi korelasi diperoleh $\mathrm{T}$ Hitung sebesar $(-2,88)$ dan $\mathrm{T}$ Tabel sebesar $(2,110)$. Nilai ini menunjukkan bahwa $\mathrm{T}$ Hitung $<\mathrm{T}$ Tabel yang mengartikan bahwa korelasi bernilai negatif. Koefisien korelasi $\mathrm{r}$ yang diperoleh bernilai negative yaitu $(-0,44)$ yang menunjukkan bahwa hubungan antar variabel lemah.

Hasil uji Anova diperoleh F hitung sebesar 3,394 dan $F$ tabel yang diperoleh dari Tabel Distribusi $F$ pada tingkat signifikasi $\alpha \quad 0,05$ sebesar 1,910. Hasil ini menunjukkan bahwa nilai Ftabel < Fhitung, sehingga jenis dan konsentrasi ekstrak gulma sebagai pestisida nabati berpengaruh nyata terhadap pengendalian hama ulat grayak.

\section{Jumlah Penyemprotan/ 5 Menit}

Tabel 7. Jumlah Penyemprotan/ 5 Menit

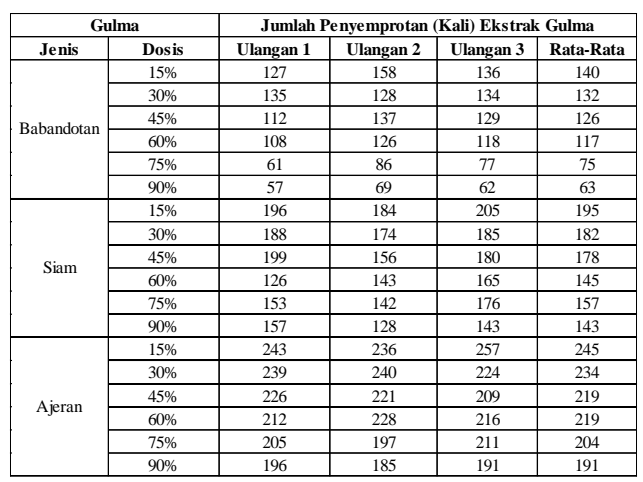

Sumber: Data Primer, 2018

Hasil penelitian menunjukkan bahwa penyemprotan terbanyak 
terjadi pada ekstrak gulma Ajeran pada konsentrasi $15 \%$ dengan ratarata penyemprotan sebanyak 245 kali penyemprotan,

sedangkan penyemprotan yang paling sedikit terdapat pada ekstrak gulma Babandotan dengan konsentrasi 90\% dengan rata-rata penyemprotan sebanyak 63 kali penyemprotan. Hasil ini menunjukkan bahwa dilihat dari jumlah penyemprotannya, ekstra gulma Babandotan 90\% merupakan yang paling dapat mengendalikan hama tercepat dari jenis dan konsentrasi ekstrak gulma lainnya.

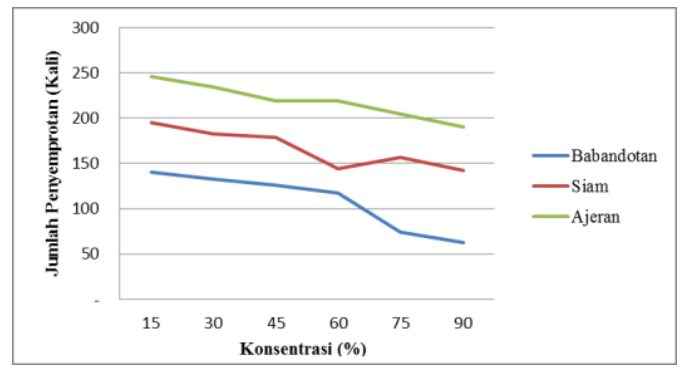

Sumber: Data Primer, 2018

Gambar 4. Jumlah Penyemprotan/ 5 Menit

Hasil grafik menunjukkan bahwa dari ketiga jenis ekstrak yang memiliki jumlah penyemprotan terbaik adalah pada gulma Babandotan. Hal ini ditunjukkan dengan pada garis grafik Babandotan yang berada paling rendah dari dua jenis gulma lainnya, yang menandakan bahwa jumlah penyemprotan paling sedikit sehingga merupakan gulma terbaik yang dapat mengendalikan hama. Garis grafik yang tertinggi terjadi pada gulma Ajeran yang mengartikan bahwa gulma Ajeran memiliki jumlah penyemprotan terbanyak dari dua jenis gulma lainnya.

Hasil uji anova diperoleh $\mathrm{F}$ hitung sebesar 54,010 dan $\mathrm{F}$ tabel yang diperoleh dari Tabel Distribusi $F$ pada tingkat signifikasi $\alpha \quad 0,05$ sebesar 1,910. Hasil ini menunjukkan bahwa nilai Ftabel<Fhitung, sehingga jenis dan konsentrasi ekstrak gulma sebagai pestisida nabati berpengaruh nyata terhadap pengendalian hama ulat grayak.

\section{Volume Penyemprotan}

Tabel 8. Volume Penyemprotan

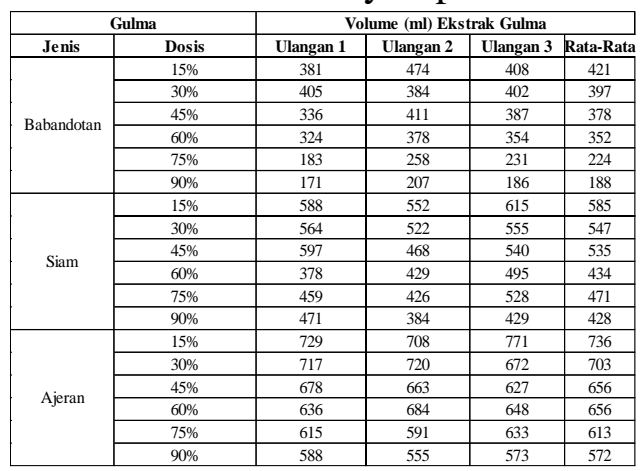

Sumber: Data Primer, 2018

Ekstrak gulma Ajeran memiliki jumlah volume ekstrak paling banyak dari kedua jenis gulma lainnya. Hal ini ditunjukkan pada garis grafik gulma Ajeran yang berada pada posisi paling atas. Volume tertinggi pada ekstrak gulma Ajeran yaitu pada konsentrasi $15 \%$ dengan rata-rata volume $736 \mathrm{ml}$ dan volume terendah Ajeran pada konsentrasi $90 \%$ dengan rata-rata volume $572 \mathrm{ml}$. Grafik ekstrak 
gulma Siam menunjukkan volume tertinggi ekstrak gulma siam pada konsentrasi $15 \%$ dengan volume 585 $\mathrm{ml}$, sedangkan volume terendah ekstrak Siam pada konsentrasi $90 \%$ dengan volume $428 \mathrm{ml}$. Volume ekstrak gulma Babandotan pada grafik menunjukkan garis grafik berada paling bawah, hal ini menunjukkan bahwa ekstrak gulma Babandotan yang digunakan memiliki volume yang paling sedikit dari jenis gulma lainnya. Volume tertinggi ekstrak gulma Babandotan pada konsentrasi $15 \%$ dengan volume $421 \mathrm{ml}$ dan volume terendah pada konsentrasi $90 \%$ dengan volume $188 \mathrm{ml}$.

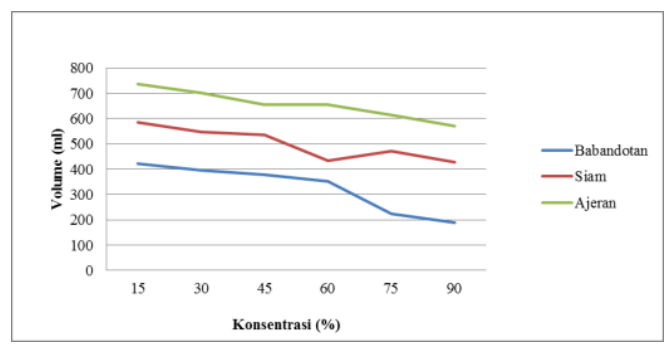

Sumber: Data Primer, 2018

Gambar 5. Jumlah Penyemprotan

\section{Gambar 5 menunjukkan} bahwa volume ekstrak gulma tertinggi pada Ajeran konsentrasi $15 \%$ dengan volume $736 \mathrm{ml}$ dan volume ekstrak gulma terendah pada gulma Babandotan konsentrasi $15 \%$ dengan volume $188 \mathrm{ml}$. Hasil ini menunjukkan bahwa ekstrak gulma Babandotan dapat mengendalikan hama lebih cepat dari dua jenis gulma lainnya.
Hasil uji anova $\mathrm{F}$ hitung yang diperoleh yaitu sebesar 54,010 dan F tabel yang diperoleh dari Tabel Distribusi $\mathrm{F}$ pada tingkat signifikasi $\alpha \quad 0,05$ sebesar 1,910. Hasil ini menunjukkan bahwa nilai Ftabel < Fhitung, sehingga jenis dan konsentrasi ekstrak gulma sebagai pestisida nabati berpengaruh nyata terhadap pengendalian hama ulat grayak.

\section{Hasil Uji BNT dari 5 Perlakuan}

Hasil pengujian dari uji BNT terbaik pada 5 perlakuan ditunjukkan pada Tabel 9.

\section{Tabel 9. Rekapitulasi Uji BNT $\alpha$ 5\%}

\begin{tabular}{|l|l|l|}
\hline No. & Perlakuan & $\begin{array}{l}\text { Hasil Uji BNT } \\
\text { Terbaik }\end{array}$ \\
\hline 1. & Ulat Mendekat 5 Menit & Babandotan 90\% \\
2. & Pertama & Babandotan 15\% \\
3. & Ulat Mendekat Akhir & Babandotan 75\% \\
4. & Waktu Kematian & Babandotan 75\% \\
5. & Jumlah Penyemprotan & Babandotan 90\% \\
& Volume Pestisida Nabati & \\
\hline
\end{tabular}

Sumber: Data Primer 2018

Hasil rekapitulasi uji BNT dari 5 perlakuan pada Tabel 9 diketahui bahwa jenis dan konsentrasi gulma yang dapat mengendalikan hama terdapat pada Babandotan $90 \%$ dan Babandotan $75 \%$ yang memiliki jumlah rekapitulasi terbaik sama yaitu dua perlakuan. Sehingga selanjutnya dilihat dengan membandingkan antar konsentrasinya. Konsentrasi Babandotan $75 \%$ lebih sedikit dari Babandotan 90\%, hal ini akan 
berpengaruh pada perhitungan nilai ekonomisnya saat pemakaian pestisida nabati. Konsentrasi yang lebih sedikit maka akan dapat meminimalisir biaya ekonomi saat pestisida diterapkan dalam pertanian. Hasil ini yang kemudian diperoleh bahwa Babandotan $75 \%$ merupakan jenis dan konsentrasi gulma yang terbaik dalam mengendalikan hama ulat grayak.

\section{KESIMPULAN DAN SARAN}

\section{Kesimpulan}

1. Pestisida nabati dari ekstrak gulma Babadotan, Siam dan Ajeran dapat mengendalikan hama dengan fungsinya sebagai reepelent (penghalau).

2. Kondisi operasi pemakaian pestisida nabati dari gulma diperoleh hasil bahwa jumlah ulat yang menjauh dari daun sawi setelah penyemprotan rata-rata sebanyak 9 ulat dari total ulat uji 10 ulat.

3. Hasil analisis statistik One way Anova diperoleh bahwa pestisida nabati dari tanaman gulma yang paling efektif mengendalikan hama ulat grayak yaitu pestisida dari ekstrak daun gulma Babandotan dengan konsentrasi $75 \%$.

4. Korelasi bernilai negatif ($0,44)$ dan memiliki hubungan yang lemah karena bernilai $>1$ antara konsentrasi pestisida nabati untuk setiap jenis gulma terhadap kematianhama ulat grayak (Spodoptera litura).

\section{Saran}

a. Adanya penelitian tentang pengaruh penggunaan campuran detergent pada pestisida nabati terhadap hasil sayuran pertanian.

b. Adanya penelitian yang sama untuk jenis hama, jenis gulma dan aplikasi tanaman sayur yang berbeda.

\section{DAFTAR PUSTAKA}

Adnan. 2011. Makalah Penggolongan Pesitisida .Online: http://www.kesmasunsoed.info/2011/05/makalah -pengertian-danpenggolongan.html. Diakses pada tanggal 29 April 2013.

Aminah. 2001.S. Rarak, D. metel dan E. prostate Sebagai Larvasida Aedes aegypti. Cermin Dunia Kedokteran No. 131

Anonim. 2017. Potensi Gulma sebagai Pestisida Nabati. Online: http://8villages.com/full/petan i/article/id/5a33c63fb4cf55bb 30d13599. Diakses pada tanggal 14 April 2018.

Anwar, Toni.2015. Hama dan Penyakit Tanaman Tomat dan Cara Pengendaliannya. Kanisius.Yogyakarta.

Burger,I.,Burger,B,V.Albrecht,C.F.S picies,H.S.C. and 
Sandor.P.,1998. Triterpenoid saponin. From Bacium gradivlona Var. Obovatum Phytochemistry.49. 20872089.

Cahyati, Resky Dwi.2014.Alkaloid (Bagian Kedua).

Online:https://www.academia .edu/21292863/alkaloid.

Diakses pada tanggal 08 Februari 2019

Dalimartha, Setiawan. 2007. Atlas

Tumbuhan Indonesia Jilid 2.

Trubus Agriwidya.Jakarta

Danar, dkk. 2014. Toksisitas Ekstrak Gulma Ajeran (Bidens pilosa L.) sebagai Insektisida Nabati dalam Mengendalikan Hama Ulat Daun Kubis (Plutella xylostella L.).Jurnal Pertanian. Universitas Jember. Jember.

Fisher, R. A.1935.The Design of Experiments. Oliver and Boyd.Edinburgh.

Fu, P.P., Yang, Y.C., Xia, Q., Chou, M.C., Cui, Y.Y., Lin G.,2002.Pyrrolizidine alkaloids-tumorigenic components in Chinese herbal medicines and dietary supplements, Journal of Food and Drug Analysis, Vol. 10, No. 4 pp. 198-211

Grainge, M., dan Ahmed, S.1988.Handbook of Plants with Pest Control Properties.Wiley Interscience. New York.
Hayati, Yulfina. 2017. Pestisida Nabati dan Aplikasinya. Online: http://nad.litbang.pertanian.go .id/ind/images/38PESTISIDA.pdf. Diakses pada tanggal 29 April 2018.

I Nyoman Wijaya, dkk. 2017. Pengaruh Beberapa Jenis Ekstrak Daun Gulma terhadapBiologi Ulat Krop Kubis (Crocidolomia pavonana F.)di Laboratorium. E-Jurnal Agroekoteknologi Tropika. Universitas Udayana. Bali.

Jumar. 2000 .Potensi Ekstrak Tanaman Obat dan Rematik Sebagai Pengendali Plutella xlostellaL. Buletin. Littro. Vol. 22 No.1, 2011, hal. 5464.Balai Penelitian Tanaman Obat dan Rematik.Bogor.

Kaizen. 2015. Hama dan Penyakit Tomat. Online: www.belajarbarenghidroponi k.com. Diakses pada tanggal 27 April 2017

Kamboj dan Saluja. 2008. "Ageratum conyzoides L.: A review on its phytochemical and pharmacological profile. Int J Green Pharm”. Online: http://www.greenpharmacy.in fo/text.asp?2008/2/2/59/4117 1. Diakses tanggal 4 Oktober 2014.

Kristofer. 2010. Definisi Pestisida. Online:

http://blogs.unpad.ac.id/kristo 
feryanuar/2010/06/13/definisi

-pestisida/. Diakses pada tanggal 29 April 2013.

Levia, Helena.2015.Identifikasi Senyawa Organik pada Tanaman

Babadotan.Online:https://ww w.academia.edu/11709215/Ta naman_Babadotan. Diakses pada tanggal 08 Februari 2019.

Malik, Harno. 2013. Bahan

Pembuatan Pestisida Nabati.

Online:

http://sigit01.blogspot.co.id/2

013/07/bahan-pembuat-

pestiseda-nabati-ajeran.html.

Diakses pada tanggal 16 April 2018.

Mardiningsih, T.L. dan S.L.T. Sondang.1993. Efikasi Bubuk Lada Hitam terhadap Sitophilus zea Mays. Prosiding seminar Nasional Hasil Penelitian dalam Rangka Pemanfaatan Pestisida Nabati. Badan Penelitian dan Pengembangan Pertanian. Balai Penelitian Tanaman Rempah dan Obat. Bogor.

Martono, B., E. Hadipoentyanti, dan L. Udarno. 2004. Plasma Nutfah Insektisida Nabati. Perkembangan Teknologi TRO XVI Edisi Pertama. Balai Penelitian Tanaman Rempah dan Obat. Bogor.
Muniappan R \& Bamba J.1999.

Biological Control of

Chromolaena odorata:

Successes and

Failures.Proceedings of the $X$ International Symposium on

Biological Control of Weeds 4-14 July 1999.Montana State University, Bozeman, Montana.USA.

Oka, I.N. 1993. Penggunaan, Permasalahan serta Prospek Pestisida Nabati dalam Pengendalian Hama Terpadu. Dalam Sitepu, D;P. Wahid; M. Suhardjan; S. Rusli; Ellyda A.W.; I.Mustika; dan D. Sutopo(Penyunting). Hal. 110.Proseeding Seminar Hasil Penelitian dalam Rangka Pemanfaatan Pestisida Nabati. Badan Penelitian dan Pengembangan

Pertanian.Balai Penelitian Tanaman Rempah dan Obat. Bogor.

Pink, A. 2004. Gardening for the Million. Project Gutenberg Literary Archive Foundation. Online: www.gutenberg.org. Diakses pada tanggal 10 Desember 2012.

Pitojo, S. 2005. Benih Tomat. Kanisius. Yokyakarta.

Pratama, B. A.2010. Efektivitas Ekstrak Daun Pandan Wangi (Pandanusamaryllifolius Roxb.) dalam Membunuh 
Larva Aedes aegypti. Skripsi. Universitas Muhammadiyah Surakarta. Surakarta.

Pratomo, Putro, Aris L.2010.Laporan Fieldtrip Pertanian Berlanjut. Online: http://id.scribd.com/doc/5027 0019/Laporan-Fieldtrip-PB.

Diakses padatanggal 20 April 2013.

Robinson ,T. 1995. Kandungan Organik Tumbuhan Tingkat Tinggi. Institut Teknologi Bandung.Bandung.

Romdonawati, Y. 2009. Ekstrak Daun Kirinyu [Chromolaena odorata (L.) R. M. King and H. E. Robinson] sebagai Larvasi dan Nyamuk Aides aegypti. Laporan Penelitian. Fakultas Matematika dan Ilmu Pengetahuan Alam. Universitas Sebelas Maret. Surakarta.

Soemirat, J. S. 2005. Epidemiologi Lingkungan. Universitas Gadjah Mada Press. Yogyakarta

Soesanto, Loekas. 2017. Pengantar Pestisida Nabati. Rajawali Pers. Jakarta.

Sonyarantri, D. 2006. Kajian Daya Insektisida Ekstrak Daun Mimba (Azadiractha indica A. Juss) dan Ekstrak Daun Mindi (Melia azedarach L.) Terhadap Perkembangan Serangga Hama Gudang
(Sitophilus zeamais mostch). Institut Pertanian Bogor.

Sultan, et al. 2016. Pemanfaatan Gulma Bandotan Menjadi Pestisida Nabati Untuk Pengendalian Hama Kutu Kuya pada Tanaman Timun. Jurnal Pendidikan Teknologi Pertanian, Vol. 2 (2016) : 77 85. Universitas Negeri Makassar. Makassar.

Suprihatin, Agung. 2013. Pemanfaatan Gulma di Halaman Kampus PPPPTK BOP Malang Sebagai Media Pembelajaran Pendidikan Lingkungan Hidup (Mata Diklat Pestisida Nabati). Pusat Pengembangan dan Pemberdayaan Pendidik dan Tenaga Kependidikan Bidang Otomotif dan Elektronika. Malang.

Wettstein, Charles J. Chamberlain. 1935. Botanical Gazette. Vol. 45, No. 1 (Jan., 1908), p. 58 Part 3. The University Chicago Press. Chicago.

Yoyok. 2012. Penggolongan Gulma.

Online: http://blogyoyok.blogspot.co.i d/2012/05/penggolongangulma.html. Diakses pada tanggal 29 April 2018 
